\title{
Hydrological models are mediating models
}

\section{V. Babel and D. Karssenberg}

Department of Physical Geography, Faculty of Geosciences, Utrecht University, Utrecht, the Netherlands

Received: 30 June 2013 - Accepted: 21 July 2013 - Published: 16 August 2013

Correspondence to: L. V. Babel (l.v.babel@uu.nl)

Published by Copernicus Publications on behalf of the European Geosciences Union.

L. V. Babel and

D. Karssenberg

Title Page

Abstract

Conclusions

Tables

14

4

Back

Full Screen / Esc

Printer-friendly Version

Interactive Discussion

\section{Figures}

$\rightarrow$

$>$

Close

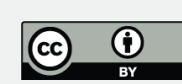




\section{Abstract}

Despite the increasing role of models in hydrological research and decision-making processes, only few accounts of the nature and function of models exist in hydrology. Earlier considerations have traditionally been conducted while making a clear 5 distinction between physically-based and conceptual models. A new philosophical account, primarily based on the fields of physics and economics, transcends classes of models and scientific disciplines by considering models as "mediators" between theory and observations. The core of this approach lies in identifying models as (1) being only partially dependent on theory and observations, (2) integrating nondeductive elements in their construction, and (3) carrying the role of instruments of scientific enquiry about both theory and the world. The applicability of this approach to hydrology is evaluated in the present article. Three widely used hydrological models, each showing a different degree of apparent physicality, are confronted to the main characteristics of the "mediating models" concept. We argue that irrespective of their 5 kind, hydrological models depend on both theory and observations, rather than merely on one of these two domains. Their construction is additionally involving a large number of miscellaneous, external ingredients, such as past experiences, model objectives, knowledge and preferences of the modeller, as well as hardware and software resources. We show that hydrological models convey the role of instruments in scientific practice by mediating between theory and the world. It results from these considerations that the traditional distinction between physically-based and conceptual models is necessarily too simplistic and refers at best to the stage at which theory and observations are steering model construction. The large variety of ingredients involved in model construction would deserve closer attention, for being rarely explicitly identifying and communicating on the many factors involved in model development might increase transparency of model building.

Hydrological models are mediating models

L. V. Babel and

D. Karssenberg

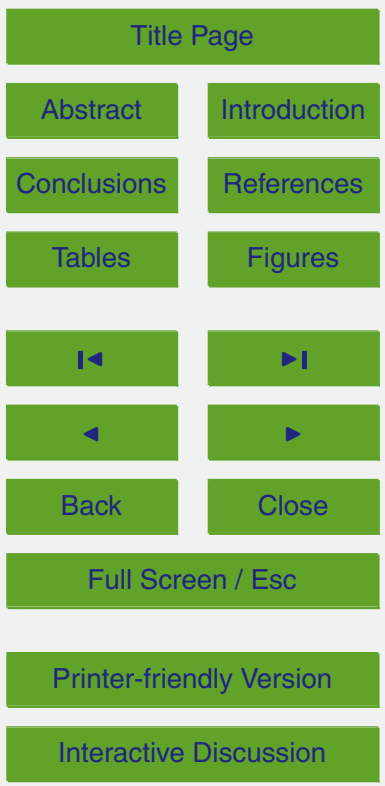




\section{Introduction}

Numerical models play a central role in hydrological research. During the last five decades, the function of models and their application in decision-making processes encountered a tremendous evolution (Winsberg, 2010; Oreskes, 1994). Nowadays an 5 important part of our knowledge of hydrology is embodied in models, and we rely on models both for our understanding of hydrological processes and for our forecasts. Some models even climbed up to standard instruments of hydrological research and are considered almost as widely applicable as theories. This new turn in scientific practice raises a number of philosophical issues associated in particular with the nature and the credibility of our numerical models. Yet in comparison to other environmental sciences, such as biology (e.g. Peck, 2004, 2012; Odenbaugh, 2005; Caswell, 1988; Wimswatt, 1987), the number of philosophical accounts of models in hydrology remains limited (see Beven, 1993, 2001, 2002; Savenije, 2009).

Existing considerations on the relationship between hydrological models, theory and observations have traditionally been conducted while making a clear distinction between physically-based and conceptual models (Sivapalan et al., 2003). Physicallybased models are typically characterized by mathematical relationships derived from physical laws. As these laws are often considered only applicable for representation of processes at a small-scale, these models are mostly distributed using a discretization in small model units. Conceptual models, on the other hand, make use of laws derived from environmental data and are lumped or semi-distributed. It is widely assumed that modelling processes at a higher level of detail leads to models with a higher degree of realism (Beven, 1989; Mulligan, 2005). Thus, physically based models have often been considered more sound, and theoretically more credible, than their conceptual counterpart (Beven, 2001). Other approaches to modelling exist, but these are mostly placed on the axis between the two extremes of purely conceptual and purely physically-based.

\section{HESSD}

10, 10535-10563, 2013

Hydrological models are mediating models

L. V. Babel and

D. Karssenberg

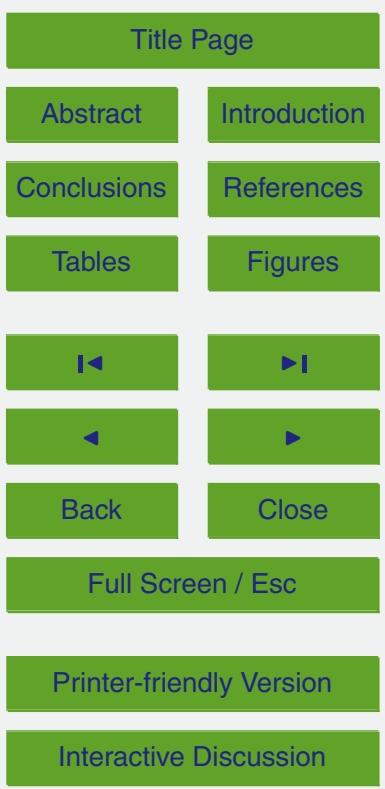


However, transcending this distinction between physically-based and conceptual models, a new approach by philosophers of science amounts to consider models - irrespective of their degree of apparent physical soundness - as "mediators" (Morgan and Morrison, 1999). The core of this approach lies in recognizing models 5 as partially independent from theory and the world; a property gained from their construction, which necessarily integrates non-deductive elements. The "mediating model" perspective resulted from a large number of case studies conducted in the fields of physics and economics. However, its implications went almost unnoticed in hydrology.

10 The objective of this article is to evaluate the applicability of the "mediating model" concept as a transcendent, global approach to hydrological models. To this aim, the characteristics of mediating models are presented and examined for both physicallybased and conceptual models, by using concrete examples from TOPMODEL (Beven and Kirkby, 1979), SHE (Abott et al., 1986) and HydroGeoSphere (Therrien et al., 2010). A short review of different accounts of models in philosophy of science is provided in Sect. 2. The properties of mediating models are presented in Sect. 3, and discussed for hydrological models in Sect. 4. We end this paper by discussing the implications of the mediating model approach for fundamental and applied research in hydrology.

\section{Scientific models in philosophy of science}

The models considered in this study are transient (temporal) mathematical models, with properties described by state variables, which are mostly spatial and changing over time as a result of a state transition function with associated parameters. Due to the complexity of the calculations and spatio-temporal variation, transient models the philosophical discussion about models is by far anterior to the development of numerical techniques. We will briefly review the evolution of this discussion

HESSD

10, 10535-10563, 2013

Hydrological models are mediating models

L. V. Babel and

D. Karssenberg

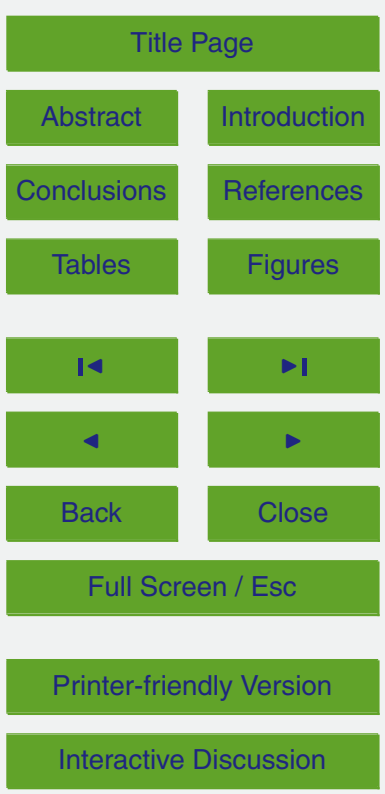


hereafter, being convinced that the novelty of the "mediating models" approach to scientific modelling is better understood when confronted to the different accounts that dominated in the past.

The appearance of models in philosophy of science coincided with the introduction 5 in fundamental physics of a large number of concepts apparently deprived of observational evidence (Hesse, 2000), of which an eloquent example is the electromagnetic wave, first conceptualized in the 19th century. In the absence of observations, pictorial and mechanical (physically built) models were massively developed in the aim of testing and validating these emerging theories (Morrison, 2007). As was the case 10 in the context of the development of the electro-magnetic theory, these could take the form of simple material models, built out of wheels and rubber bands (Harman, 1982). However, far from remaining a side help to theoretical development only, model construction was already considered by some as a philosophical requirement to theorization. For Lord Kelvin, the ability to construct a mechanical model as an application of a theory was indeed a fundamental condition to the validity of the theory under consideration. This condition was as important as to lay at the core of his opposition to James Clerk Maxwell upon electromagnetism (Morrison, 2007; Smith and Wise, 1989); there was no mechanical model of Maxwell's electromagnetic theory, and so the theory itself could not be deemed credible.

It is however not until the beginning of the 20th century that models started to be actively considered by philosophers of science. This interest found its roots in the logical movement, initiated by the publication of "Principia Mathematica" by Whitehead and Russel in 1913 - a philosophical milestone which aimed at anchoring all mathematics in first order logics. Under the emerging current of logical empiricism, philosophy of science was soon to be understood as the logical analysis of scientific theories (Wallace, 1996; Giere, 2000). If models were studied, it was strictly for the purpose of detailing their logical relationship to theories. Nothing surprising, then, that models were assigned a significantly different definition - let alone function - in this logical frame than they would carry in nowadays' scientific practice.

\section{HESSD}

10, 10535-10563, 2013

Hydrological models are mediating models

L. V. Babel and

D. Karssenberg

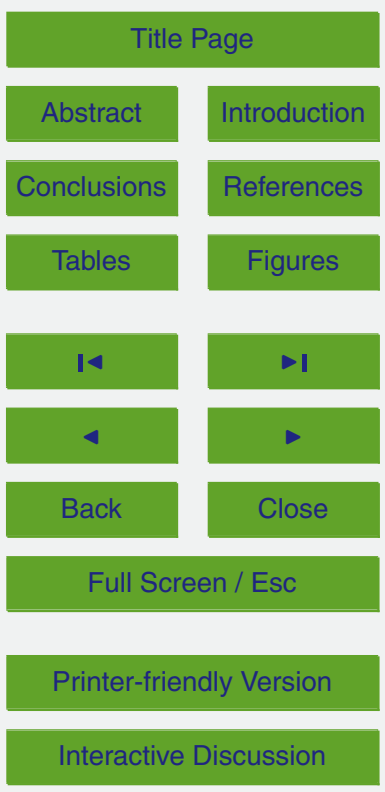


In logical empiricism, two views regarding models cohabited during the past century. The first and earliest one, the so-called syntactic view, considered models as linguistic elements enabling the interpretation of theories. Theories - sets of axioms - were deemed to encompass entities that could not be directly related to empirical evidence. In order to relate theories to observations, correspondence rules were needed to "translate" these non-observable entities towards the world. For logical empiricists, these correspondence rules were models. A core aspect of this view, certainly complicating its application in everyday scientific practice, was however that models were then considered to be fully deduced from theory, and hence possessing an identical logical structure as theory. In fact, the definition of theories themselves in first-order logics was already so troublesome (Morrison, 2007) that the syntactic view was progressively abandoned in favour of a second approach - the semantic view.

The semantic view avoided the problem of the expression of theories in first-order logics by reversing the equation. Models were not defined by theories anymore; 15 instead, theories were defined by models. Defining a theory, or so did the semantic view state, amounted to specifying a family of models - that is, an entire set of interpretations of the axioms of the theory. The problem of the definition of theories in first-order logics was solved hereby, but not the main difficulty regarding the application of this philosophical account: the logical structures of models and of their associated theory were still considered fully identical.

The syntactic and the semantic views could appear diametrically opposite. But if the two sides of the equation - theories and models - are indeed inverted, the equation itself stays the same: there really is nothing else in a model, or in a theory, than theory, or models. This aspect renders either view just as inadequate from the perspective of actual scientific practice. Are our hydrological models really constructed out of theory alone? Is the appreciation of models as sole interpretations of theoretical axioms not genuinely reductive of their function in science?

The semantic approach dominated the philosophical conception of models during the 20th century (Mattingly, 2005). However, the influential work of Nancy Cartwright
HESSD

10, 10535-10563, 2013

Hydrological models are mediating models

L. V. Babel and

D. Karssenberg

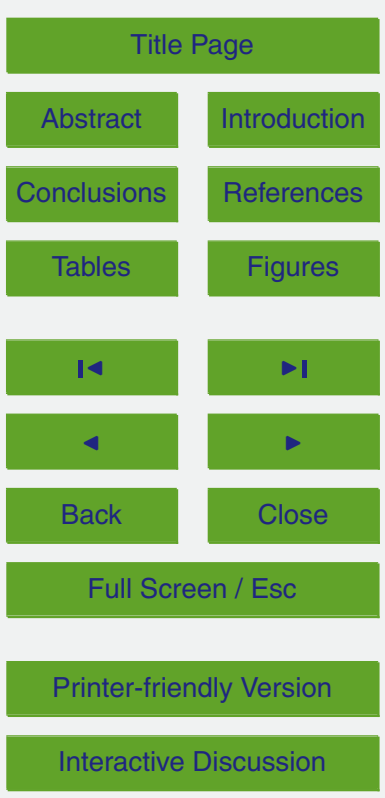


(1983) and Mary Hesse (2000) marked a shift from the "logical" analysis of science to the empirical study of the actual process of theory making - and model use in science. The omnipresence of models in scientific practice and the issues linked to their use in policymaking was increasingly calling for a new philosophical account 5 of models, somehow closer to actual scientific activity. In this regard, an important rupture was initiated in the 1990s by breaking down the logical link between theory and models (and inversely) by adding external entities to the equation. Models are then considered as the result of a complex integration of miscellaneous elements dependent on mathematical, technological, economical and sociological constraints, 10 which necessarily renders them partially independent from theory, but also from data. As expressed by Morrison and Morgan (1998):

"(...) models, by virtue of their construction, embody an element of independence from both theory and data (or phenomena): it is because they are made up from a mixture of elements, including those from outside the original domain of investigation, 15 that they maintain this partially independent structure".

These characteristics lead Morton (1993) and Morgan and Morrison (1999) to define models as "mediating". Models function as mediators between theory and the world, enabling us hereby to use them as instruments of enquiry about both domains. If models did not convey this mediating facet - if models were purely deduced from either theory, as logical empiricist accounts would suggest, or from empirical data alone - how could one indeed possibly gain any form of novel knowledge not yet encompassed in textbooks from their manipulation? How could we attempt to test the applicability of theories, if models were nothing else than theory? And similarly, how could we aim at representing the world, if models really were the world?

\section{Mediating models}

In regard to the long prevailing approach of models as deductive interpretations of theories, the fundamental novelty of the "mediating models" concept lies in the intermediate position it confers to scientific models. Models are located between theory
HESSD

10, 10535-10563, 2013

Hydrological models are mediating models

L. V. Babel and

D. Karssenberg

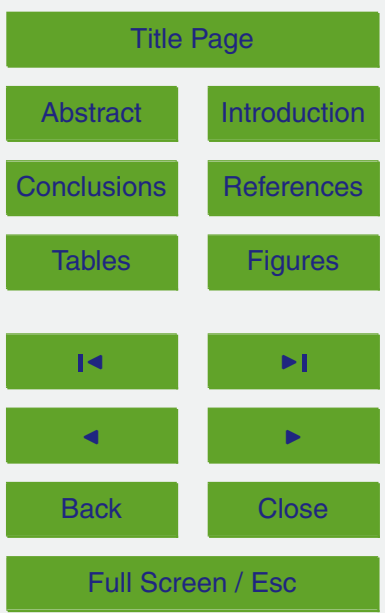

Printer-friendly Version

Interactive Discussion 
and the world; this position renders models only partly dependent - and hence at the same time partly independent - of both domains. The mediating property of models results in three main characteristics, presented hereafter. We will illustrate these characteristics with widely known examples from physics and economics, and 5 then evaluate hydrological models against the same set characteristics.

The relevance of the properties of mediating models for hydrology is examined through examples from three hydrological models: TOPMODEL, SHE and HydroGeoSphere. TOPMODEL (TOPography based hydrological MODEL, Beven and Kirkby, 1979), developed by Keith J. Beven and Mike J. Kirkby and first presented in 101979 , is a conceptual hydrological forecasting model. The sub-basin is considered as a lumped system and consists of three stores. Quick response flow is expected to be the result of the saturation of a given area, the "contributing area", which size is a function of the topography.

SHE (Système Hydrologique Européen) was developed by the Danish Hydraulic 15 onstite, the British Institute of Hydrology and the French SOGREAH from 1976 onwards (Abott et al., 1986). SHE is a distributed catchment modelling system in which precipitation, interception, evapotranspiration, snowmelt, surface flow and subsurface flow are modelled as separate components. The model area is discretized with an orthogonal grid in the horizontal direction and superimposed horizontal layers in the vertical direction.

HydroGeoSphere, one of the most complex surface and subsurface flow models currently available, was constructed as an extension of the FRAC3DVS groundwater flow code developed by Therrien (Brunner and Simmons, 2012), to which the surface domain has been added. HydroGeoSphere is considered as a fully integrated model, for rainfall is allowed to be partitioned in a physically realistic way into overland flow, evapotranspiration and groundwater recharge. The surface and the subsurface domains are coupled by making use of flow exchange terms (Brunner and Simmons, 2012).

\section{HESSD}

10, 10535-10563, 2013

Hydrological models are mediating models

L. V. Babel and

D. Karssenberg

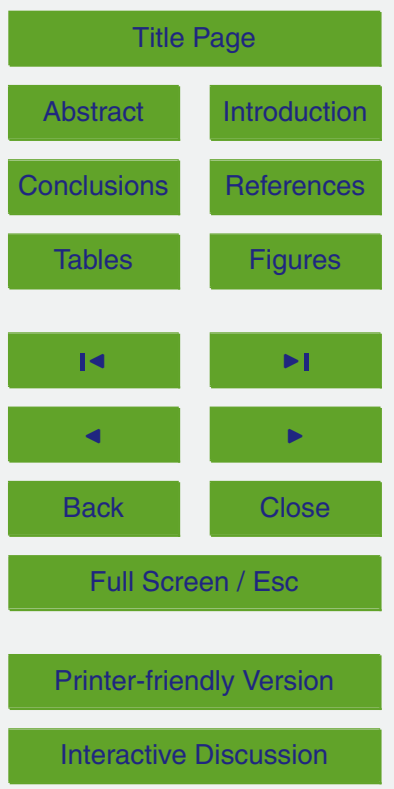




\subsection{Models cannot be deduced from neither theory nor the world alone}

The first characteristic of mediating models is their dependence on both theory and empirical data. In the broad range of scientific models, the model of the pendulum (Morrison, 1999) is often regarded by philosophers of science as one of the uttermost 5 theoretically-based specimen. In fact, identifying in it anything else than theory appears to be particularly troublesome, if not impossible at first glance. Not only is the motion of the pendulum described by Newtonian mechanics, but the many corrections that need to be incorporated in the model to account for the real behaviour of the empirical object (e.g. buoyancy, drag force, damping force) find their roots, too, in background theory 10 (Morrison, 1999). So how could we pretend that the model of the pendulum is not fully deduced from theory? Would it not be a perfect counter-example to the "mediating model" concept, i.e. a model that, rather than mediating between theory and the world, would stick to one of these two domains - in this case theory? To address this issue requires coming back to logical positivism. We showed that the deductive relationship between theory and models was understood in a strict sense: models were considered to be fully suggested by the theory. That is, the theory did not only provide all theoretical expressions required for the construction of the model, but also all reasons for which notions, corrections and approximations to use. Yet this is resolutely not the case for the pendulum. The corrections are accounted for by the theoretical background; but in no place does Newton mechanics indicate which of these should be added in order to describe a real pendulum (Morrison and Morgan, 1999). Rather, the choice of the appropriate corrections intervenes upon considering the real object that we wish to model. It is because we observe that the pendulum bob is of finite size and that the wire is stretching that we know which corrections to incorporate. If observations are steering the integration of the model's components, then the model of the pendulum - the flagship of theoretical models - can only be said to be partly deduced from theory. Yet not all models are constructed with the intention of deducing them as closely as possible from theory. In fact, some models are even expected not to contain any
HESSD

10, 10535-10563, 2013

Hydrological models are mediating models

L. V. Babel and

D. Karssenberg

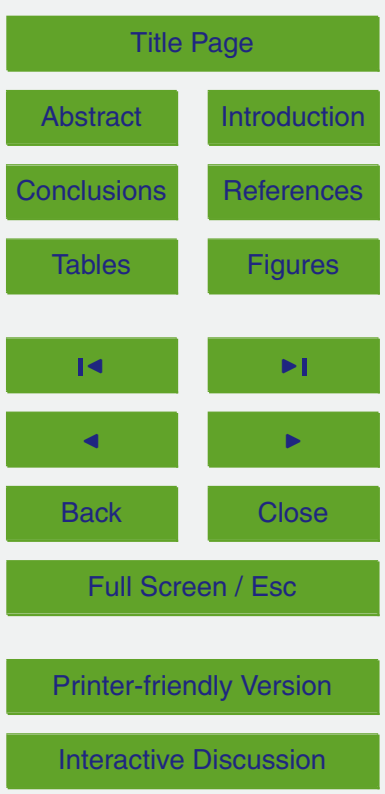


theoretical notions at all: they are considered as being built from empirical data alone, without a priori conceptions of the system under study. The economic barometer (Harvard A-B-C curves) developed by Persons (1919) (Fig. 1) is a rather extreme example of such empirical models, and is particularly interesting in this regard. Its 5 construction, a type of curve-fitting exercise, followed two main steps. First, time series of twenty economic variables were low-pass filtered in order to isolate a cyclical movement - the business cycle (Morgan, 1990). Second, the variables were classified into three economical indexes. This was achieved by comparing the timing of their fluctuations, a task carried out by observers moving the time series on top of each 10 other over a light box (Morgan, 1990). The obtained barometer could then be used to predict the upward or downward movement of an index on the basis of the current trends of the other ones.

Persons' objective was clearly to let the data speak from themselves, without theoretical pre-conceptions (van de Bogaard, 1999). But did he succeed? Probably not: the economic barometer was necessarily influenced by theory. The idea of isolating a cyclical movement, in particular, could not be motivated by the data alone, but was rather inherited from Marshallian theory (van de Bogaard, 1999). The design of the measurements, as well as the choice of a particular time scale, is, too, a reflection of theoretical conceptions of the time. Indeed, the simple act of collecting data and arranging them in a specific manner is always integrated in a conceptual framework, which is necessarily pre-existing and guiding the modeller's choices (Kirk Nordstrom, 2012).

Now, let's return to hydrology. This short review of modelling practices in other disciplines shows us that models are really a mixed bag of components from theory and the world. Even the models of the pendulum and the economic barometer, being located at the two extremes (theory or world) of modelling approaches, are not derived from theory or the world alone. So what is the situation with hydrological models?

As stated in the introduction, a relatively clear distinction is generally made in hydrology between physically-based and conceptual models. This distinction is closely
HESSD

10, 10535-10563, 2013

Hydrological models are mediating models

L. V. Babel and

D. Karssenberg

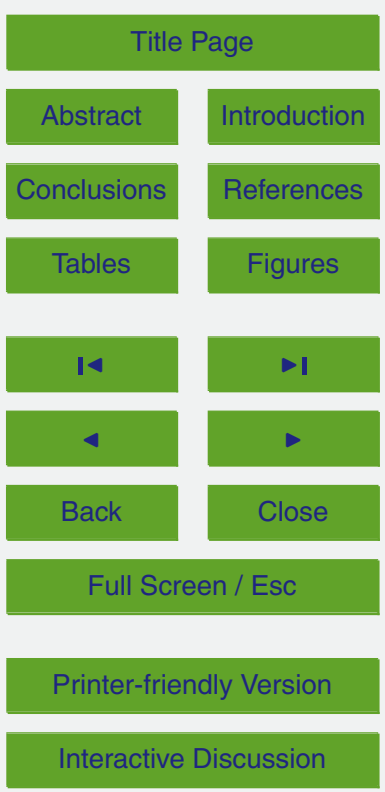


linked to the relationship of both classes of models to theory and observations. The physically-based modelling approach intends to derive the model equations from theory to the largest extent possible, while conceptual modelling employs higher-order laws derived largely from environmental data. Hence the two classes have opposite 5 starting points: theory in the case of physically-based models, and observations in the case of conceptual models. The question now inevitably amounts to assess to which degree hydrological models belonging to either class remain defined from theory or the world alone.

Let's first consider the physically-based models. Are they fully independent of the 10 world? One aspect of these models is that they are not tailored to a particular domain or purpose. The use of fundamental hydrologic laws mainly derived from physics, which are expected to be valid in a wide range of conditions, renders them potentially applicable to a large diversity of current and future hydrological systems. In this regard, physically-based models could be considered to reach, at the moment of their development, a relatively high degree of independence from observations. This multifunctionality and adaptability to different contexts is often regarded as a main argument for the development of such complex models: the scientist is provided with a versatile tool, encompassing physical descriptions of processes, which can be customized to the actual purpose of the study. Yet although the formalization in a computer code of low-level laws and of their interactions can remain close to the highest level of physical understanding that we have about the system (theory), observations (the world) will necessarily interfere with the structure of the model at the moment of its application. Actual data availability never matches the mostly tremendous amount of input data, which would be required to simulate the processes at the exact level of theoretical knowledge that we possess about them. Simplifications are hence inevitable. Some of these simplifications might be physically-based. But just as in the case of the model of the pendulum presented above, theory still does not provide any instruction about which simplifications to use; the choice of the simplifications will be steered by the confrontation to empirical data alone. Simplifications might also occur on the
HESSD

10, 10535-10563, 2013

Hydrological models are mediating models

L. V. Babel and

D. Karssenberg

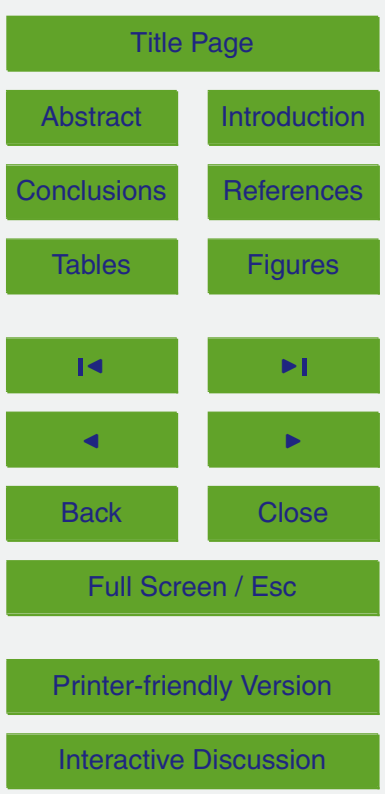


data themselves: if empirical data exactly matching the requirements of the model are missing, model inputs are estimated on the basis of indirect sources, such as literature, or by interpolation or extrapolation of observations. Elsewhere, processes are parameterized, for instance through upscaling or downscaling techniques, because 5 no measurements are available at the support (representative area or timespan) required by a physically-based description of the process. Through simplifications, the initial relationship to theory is softened and decreased, constrained by the world. The relationship of physically-based models to theory and data can hence be divided into two stages of model construction. In the first stage, which corresponds to the 10 formalization of physical knowledge in a computer code, the model could, in the ideal case, represent the highest degree of theory available. In the second stage - the customization of the model to a particular situation for application - the modelling becomes influenced by the amount and type of observations, either because the model structure is adjusted to the available observations, or because model inputs are provided derived from observations that do not match the theoretical requirements posed by the physically-based equations. This decrease in physicality is explicit in the case of HydroGeoSphere, a model of the newest generation of physically-based, fully integrated hydrological models. In a review article, Brunner and Simmons (2012) argue:

"Obviously, HGS is a complex code ... A justified and often raised criticism of 20 complex models is that the amount of parameters required often exceeds the resources and capabilities to obtain them, and the long run times of physically based models make parameter estimation difficult or even impossible ... [However] we prefer to have a powerful model with more functionality at our disposal, even though we might not use all the features all the time."

This citation illustrates the two characteristics of physically-based models presented above. First, physically-based models have generic applications and are particularly versatile. Second, the degree of physicality decreases when these models are confronted with real data: data constraints require the scientist to adapt the model to the relevant situation by disregarding some of its features.
HESSD

10, 10535-10563, 2013

Hydrological models are mediating models

L. V. Babel and

D. Karssenberg

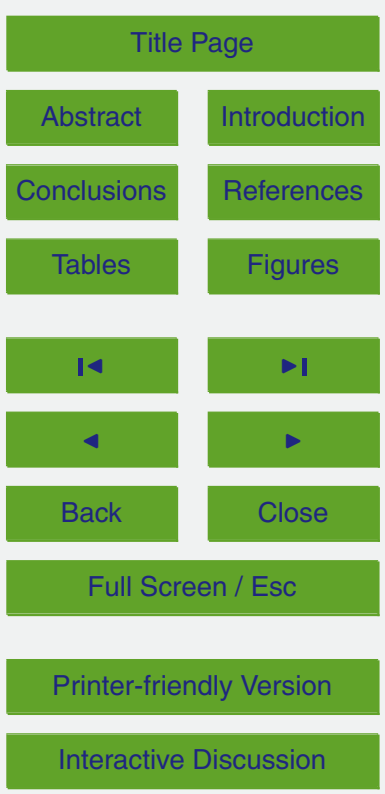


The situation is significantly different for the case of conceptual models. Initially intended for a particular function at a particular geographical scale, their structure is determined by observations from the beginning on. TOPMODEL, for example, was developed for certain catchments located in the UK (Beven, 2001). Because 5 the data were scarce, expensive and time-intensive, Beven and Kirkby attempted to build a model minimizing the number of parameters while still guaranteeing their physical significance, notably by using one of the most reliable and most easily obtained parameter for exploitation, topography (Kirkby, 1997). The representation of the system was hence immediately limited and steered by the available data. At the 10 same time, it appears relatively clear that this representation could not be attained without pre-existing theoretical knowledge of runoff mechanisms. It is thus both on the basis of the existing observations and the background theory that TOPMODEL was developed. If we compare this approach with physically-based models, the decisive aspect here is that because conceptual models are tailor-made, their theoretical and observational components are not prone to modifications when the model is applied to the data it was intended for. When used for a real catchment, the conceptual model will in principle be just as theory-based and observation-based as it was at the moment of its development, given that its structure was constructed to match the local conditions. This is fundamentally opposite to physically-based models, where the degree of physicality decreases upon confrontation with real conditions.

We have chosen to illustrate the dependence of conceptual models on both theory and data by the well-known example of TOPMODEL. However, TOPMODEL does not represent the empirical extreme of hydrological modelling; many models could be defined as relying to a significantly larger extent on empirical data. Neural networks, for example, link drivers to outputs through a network of nodes, where the network is constructed by training on empirical data only (Abrahart and See, 2007). No equations derived from theory are used, so that neural networks could appear to be fully empirical. But are they? The situation is in reality not different from the business barometer presented above. The choice of inputs and their connection to the network
HESSD

10, 10535-10563, 2013

Hydrological models are mediating models

L. V. Babel and

D. Karssenberg

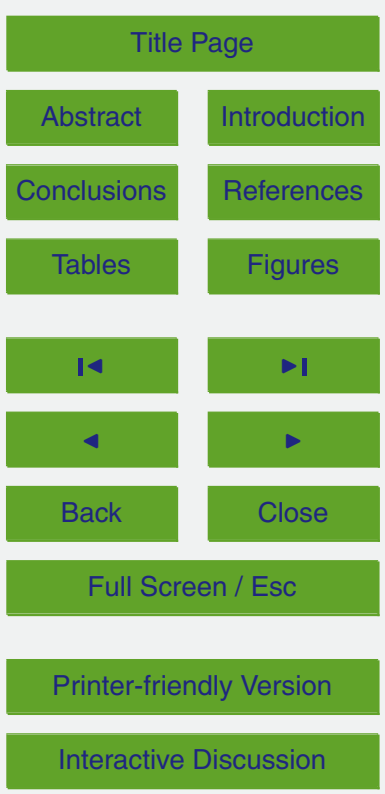


are necessarily motivated by theoretical conceptions of the user: in no way do they emerge from the data set only.

From the newest generation of physically-based models to conceptual models, up to neural networks, one characteristics appears to transcend all classes of hydrological 5 models: each of them, whichever its kind, depends on both theory and empirical data. In physically-based models, empirical data constrains model construction at the moment of the application of theoretical expressions to a real-world situation. In conceptual models, theory steers the choice of variables and mechanisms to consider. All hydrological models are hence influenced by both domains - theory and the world.

\subsection{Models are the result of a complex integration of miscellaneous elements}

We showed in the previous section that models necessarily contain both theoretical notions and observations. Yet the mediating models concept states that, to function as mediators between theory and the world, models have to encompass elements that are external to either domain. This independence enables them to carry the function of 5 instruments with an important role in hypothesis testing, theory development, and data provision. The question arises whether hydrological models contain such elements that are external to either theory or the world. We address this question by looking at five elements that have no or very limited connection to hydrological theory or data. These are: past experiences, model objectives, personal knowledge and abilities of the 20 modeller, computer resources and software resources.

Past experiences relate to the knowledge gained through the development and the application of previous models. Successful modelling experiences suggest processes or components to be modelled in a certain way, while previous failures identify areas that need additional attention, possibly calling for novel methods. The construction of SHE in the late 1970s particularly enlightens the role of precedent experiences in hydrological modelling. Observations and current knowledge of the time were showing that traditional conceptual rainfall-runoff models did not account for a certain number of processes. Also, the application of these traditional models was often prohibited

Hydrological models are mediating models

L. V. Babel and

D. Karssenberg

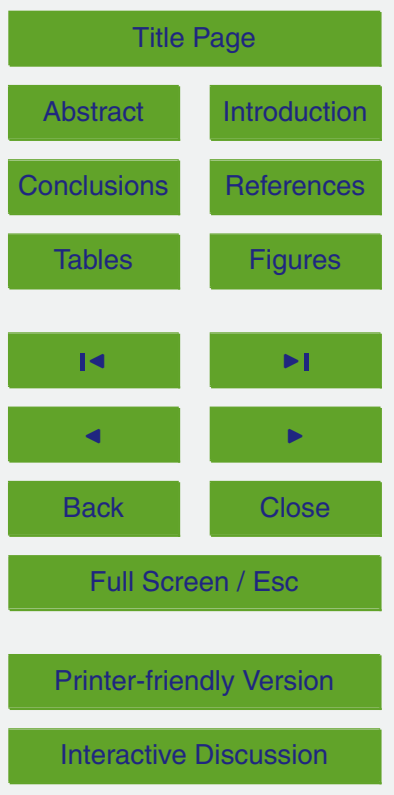


by a lack of data, in particular long-term hydrological and meteorological records; it was believed by the time that more flexible, physically sound models would require less calibration data (Abbott et al., 1986). The use of existing rainfall-runoff models was hence revealing inadequacies, which needed to be overcome. Overcoming these 5 drawbacks was the main motivation for the construction of SHE. A similar and strong influence of previous modelling attempts can be observed in the TOPMODEL project, as illustrated by the following citation (Kirkby, 1997):

"In the late 1960s, it became clear that the standard forecasting models used in engineering hydrology .... were too complex to be applied objectively and that 10 the processes that they represented were not always based on physical realities observed in the field. ... For a geomorphologist, the existing hydrological models, by not representing real processes, also provided a particularly poor basis for understanding the critical role of surface and subsurface water in driving hillslope sediment transport. This intellectual climate encouraged a search for novel hydrological models that were 15 both simpler in structure, and had a closer relationship to the physical processes observed... Part of the rationale for TOPMODEL was as a crucial product of that search."

TOPMODEL was hence developed with the aim of striking a balance between the traditional rainfall-runoff models and the new incentives of the time to anchor hydrological modelling in a more solid physical basis. Just as for SHE, past experiences and current developments laid at the core of the motivation of model construction.

A second element largely steering and constraining model construction consists of the objectives for which the model is designed. The intended function of the model will contribute to selecting the processes and variables to be represented, the scale at which processes are modelled, the amount of physics used, and various other less significant choices. For a given level of theoretical knowledge and data availability, totally different models may be constructed depending on, for instance, whether the objective of the study is to forecast, or to represent the system as accurately as possible in order to understand its behaviour. TOPMODEL, which was intended for

\section{HESSD}

10, 10535-10563, 2013

\section{Hydrological models are mediating models \\ L. V. Babel and \\ D. Karssenberg}

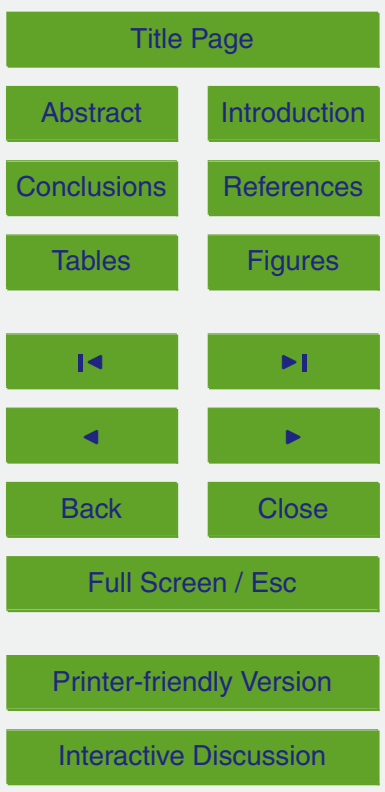


simulating the hydrological response of ungauged basins (Beven and Kirkby, 1979) hence called for a fundamentally different model structure than SHE, designed to account for pollution and deforestation problems (Abbott et al., 1986). It should be noted that the objectives of model construction are tightly coupled to the role of 5 antecedent models and experiences presented above. In the case of SHE, just as in the case of TOPMODEL, the draw-backs of conceptual rainfall-runoff models motivated the construction precisely because the objectives - distributed hydrological modelling in order to assess environmental problems (Abbott et al., 1986), or the understanding of the role of (sub) surface flow in triggering sediment transport (Kirkby, 1997) - did not - match the function of available hydrological models.

Less easily identifiable in the hydrological literature, but not less present in model construction, are the personal knowledge and abilities of the modeller. Model building remains a human, hence subjective activity. Along his or her career, the modeller will have developed an own understanding of hydrology. Wherever simplifications are 15 required, the representation of the system might be driven by his or her feeling, or "physical intuition" (Winsberg, 2010), about the validity of the assumptions that might be used. Technical abilities - e.g. proficiency in a certain type of software, understanding of numerical techniques - may additionally influence the framing of the model into a particular numerical environment.

20 But rather than to be confined to the expertise of one individual only, model construction is largely the product of a social activity, too. Decisions regarding the representation of the system or the use of softwares are made as a function of the group (research institute, firm, hydrological society, country) the modeller belongs too. Aside from purely technical - the group might be using a certain programming

language, software resource and model structure - this influence may also be of a more philosophical kind. The construction of the model might be inserted into a certain modelling current, reflecting the priorities of the group: the quest towards more physicality in hydrological models, the objective of modelling hydrology at a global scale, the question how catchment evolution causes systemic change of
HESSD

10, 10535-10563, 2013

Hydrological models are mediating models

L. V. Babel and

D. Karssenberg

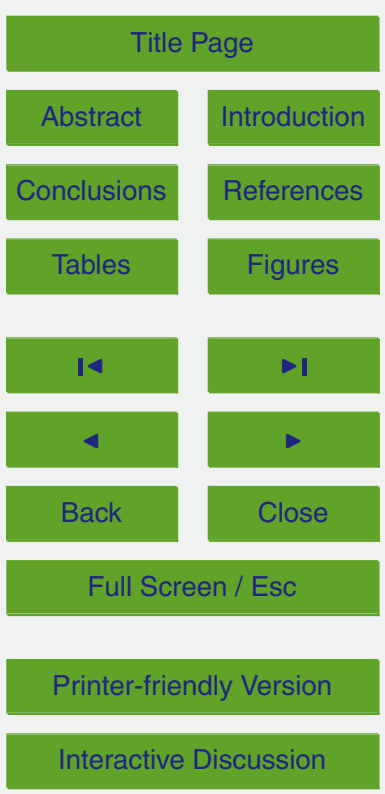


hydrology. This conceptual framework of the group will influence the objectives of model construction, along with the general modelling approach.

The elements we treated so far were mainly related to the sociological context of model construction. Yet to modellers of all fields, the most apparent, easily identifiable 5 element constraining and steering model construction is without doubt linked to technological aspects. We will focus here on hardware and software resources.

Hardware and software resources exert a particularly high influence on the construction of physically-based models by constraining the range of possibilities. Even when data availability would be high enough to enable the use of the most 10 accurate physical description at the scale of interest, simplifications might be needed because of the intractability of numerical solutions. These simplifications can range from the use of mathematical approximations to disregarding processes deemed too computationally intensive; ultimately, computational limitations might constrain the modeller to use a coarser grid size or a wider temporal scale. Yet with computation 15 power so far doubling every two years (Moore's law), the constraints exerted by computer resources on model construction evolve on a continual basis and strongly influence new model development by opening up new horizons. It appears clear that irrespective of theoretical knowledge and data availability, a model of similar complexity as HGS could simply not have been conceived at the time SHE was constructed, in the 20 late 1970s.

Equally large steps have been made in software development over the last decades. In early days of hydrological modelling, models were programmed in lowlevel languages such as Fortran and $\mathrm{C}$. The development of higher level programming languages, e.g. Matlab (Matlab, 2012), Python (Python, 2012), $R(R, 2012)$ and 25 special purpose languages for spatio-dynamic modelling such as PCRaster (PCRaster, 2012), which embed numerical solutions into functions, considerably simplify model construction and the modification of existing models (Karssenberg, 2002). At the same time, conversion of models from one programming language to another is particularly troublesome, which comes with the risk of trapping models into a certain software

Hydrological models are mediating models

L. V. Babel and

D. Karssenberg

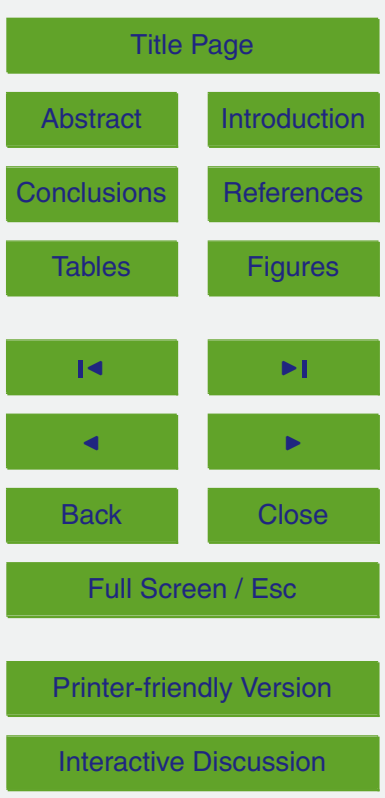


environment. Model development might then be hindered by the software used to program the model. The type of grid used in large-scale, global models perfectly exemplifies the influence of software resources on model construction. The advantage of using hexagonal grids (e.g. Lehmann and Or, 2012), for which the cell size remains 5 approximately constant over the globe, is widely acknowledged. Nevertheless, the large majority of large-scale models still use orthogonal grids: programming languages adapted to hexagonal grids are simply lacking.

We have identified at least five elements constraining and steering the construction of hydrological models: past experiences, model objectives, knowledge and preferences 10 of the modeller, computer resources and software resources. These elements intervene in model construction by suggesting development upon particular model processes or components, calling for a structure customized to the model function, motivating approximations and simplifications, limiting the level of detail of modelling or spatial extent, as well as simplifying or complicating the introduction of novel representations. They are hence an inherent part of model construction and largely conditioning the resulting model structure. Yet none of the elements mentioned above can be considered as belonging to either theory or observations. These various elements are external to both domains; thus they confer to the models a form of independence towards theory and the world. It is this partial independence which

\subsection{Models are instruments of scientific inquiry}

The semi-autonomous property of models towards theory and the world, which results from the diversity of their components, enables us to learn about both domains through the manipulation or application of models.

25 Empirical data cannot directly be used to test a theory. Applying pendulum velocity data to Newton's laws, for example, would not enable gaining any insights into the theory and its correct depiction of the reality. Whenever the theory itself becomes the subject of study, a model - in this case, a model of the pendulum - is required

\section{HESSD}

$10,10535-10563,2013$

Hydrological models are mediating models

L. V. Babel and

D. Karssenberg

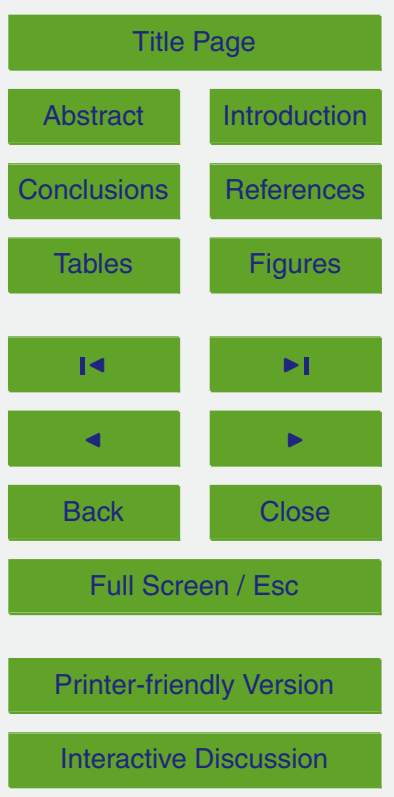


to transpose theory to the real world and enable the confrontation to empirical data. Through the manipulation of a model, this confrontation can, in turn, reveal processes that are not accounted for by existing theories and suggest theoretical development. A model used for this purpose carries the function of an instrument, mediating from the 5 world (empirical data) towards the theory that is subject of inquiry.

In hydrology, this model purpose is pursued mostly by using physically based models; conceptual models are generally considered to encompass too important simplifications of the physical system to be suitable to this end. A particularly enlightening use of the "world to theory" mediating property of hydrological models 10 can be found in virtual laboratories (Weiler and McDonnell, 2004; Sivapalan, 2005). By the capability of models to interlink different sub-processes, models can be constructed that represent large systems. Virtual laboratories are models of the entire system under study, encompassing the current (theoretical) knowledge of the system, its processes and their interactions. Their objective is precisely to test existing theories and generate new ones: by making use of empirical or synthetic data sets, the response of given processes to different inputs or boundary conditions is examined. In recent years, a large number of studies have been conducted with HydroGeoSphere functioning as a virtual laboratory, enabling new knowledge gaining in as various domains as e.g. wetland systems (Frei et al., 2012), soil water dynamics (Carrera-Hernandez et al., 2012) and stream flow (Partington et al., 2011).

However, the focus of scientific inquiry might equally well lie on data, too. Due to economical or methodological constraints, empirical data are not always available at the space and time resolution required for their application. Situations are even encountered where gaining empirical data in the field is simply impossible: this is the case for many variables of past systems, for hydrological forecasts and for evaluation of scenarios. In such situations, models can be used to simulate the missing data on the basis of existing knowledge of the system. In other words, models are then functioning as measurement devices, used to get empirical data where these cannot be obtained by observations. But even when observations are available, simulating data on the

Hydrological models are mediating models

L. V. Babel and

D. Karssenberg

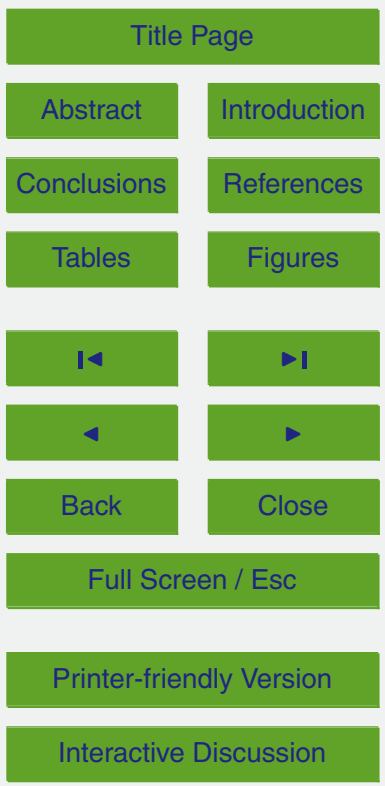


basis of theory has been shown to be useful: this is particularly the case when the quality of the observations is subject to evaluation. Actual empirical data and model outputs can then be compared in order to assess possible flaws in the measurements (e.g., Wanders et al., 2012).

$5 \quad$ When used to obtain additional measurements - either to fill missing data or to evaluate existing observations - models can be considered to mediate from theory towards the world. We showed above that empirical data could not be simply applied to theory in order to gain insights about the same theory. Here too, theory cannot be expected to generate measurements by itself: a representation of the system - a model 10 - is required to transpose theoretical knowledge to the real world. Only then can data be gained on the basis of existing theories, via the model acting as a measuring instrument.

Both conceptual and physically-based hydrological models can be appropriate for this task. Obtaining measurements is one of the objectives of TOPMODEL, which aims at modelling the hydrological response of ungauged catchments (Beven and Kirkby, 1979). But also as complex physically-based models as HydroGeoSphere (Brunner and Simmons, 2012) mediate in this direction, as is demonstrated by the application to groundwater recharge during past glaciations (Lemieux et al., 2008) and future climate conditions (Goderniaux et al., 2009).

We showed that the use of hydrological models intervenes in theoretical developments and in theory testing as well as in research about empirical data. We distinguished two directions of model application: from the world towards theory, and from theory towards the world. In these two directions, models convey the role of mediators for enabling the transposal and application of one domain (theory or the world) to the other. Indeed, empirical data could not be directly applied on theory to test the theory itself; nor could theory generate new data on its own. It is because models encompass - next to theory and empirical data - a large mixture of elements situated outside of these two domains, that the mediation between theory and the
HESSD

10, 10535-10563, 2013

Hydrological models are mediating models

L. V. Babel and

D. Karssenberg

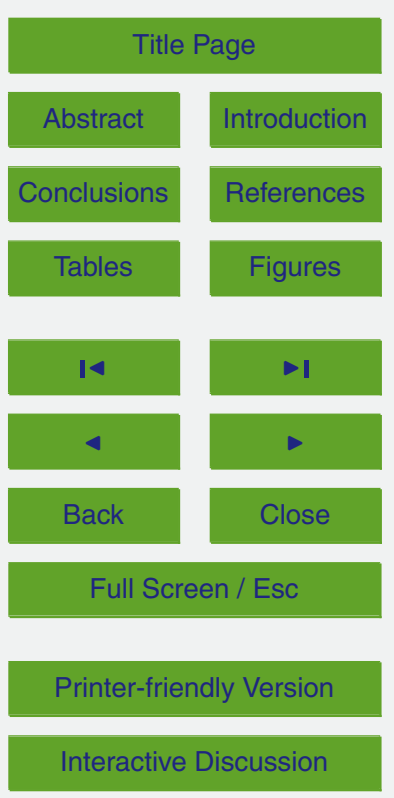


world is rendered possible through the use of models. In this regard, models can be considered as instruments of scientific inquiry.

\section{Discussion and conclusions}

Despite the increased importance of models in decision-making processes, very few 5 philosophical accounts of models exist in hydrology. Philosophers of science have traditionally considered models from the perspective of their logical relationship to theory only, which proved particularly distant from the actual concern of scientists. By transcending disciplines and offering a comprehensive approach of the construction and the role of models in science, the "mediating models" concept developed by Morgan and Morrison (1999) shed a new light in this relatively scarce environment.

The aim of this article was to assess the applicability of the "mediating models" concept to hydrology. We confronted the hydrological models TOPMODEL, SHE and HydroGeoSphere, each showing a different degree of apparent physicality, to the three main characteristics of the "mediating models" concept. We showed that irrespective of their kind - whether physically-based or conceptual - all models considered depended on both theory and empirical data. Even HydroGeoSphere, of the latest generation of physically-based models, is necessarily steered by the amount and type of available observations. Conceptual models, from TOPMODEL to the extreme example of neural networks, are not exempt from theory either: preexisting theoretical knowledge is already required for as basic a step as the choice of inputs. Additionally, we identified five elements external to theory and observation, yet constraining and steering powerfully the construction of hydrological models: past experiences, model objectives, knowledge and preferences of the modeller, computer resources and software resources (Fig. 2). We showed that hydrological models can be considered In the first case, models act as measurement instruments, used to gain data on the basis of existing theories. In the second case, models are used to transpose theory to 10555
$10,10535-10563,2013$

Hydrological models are mediating models

L. V. Babel and

D. Karssenberg

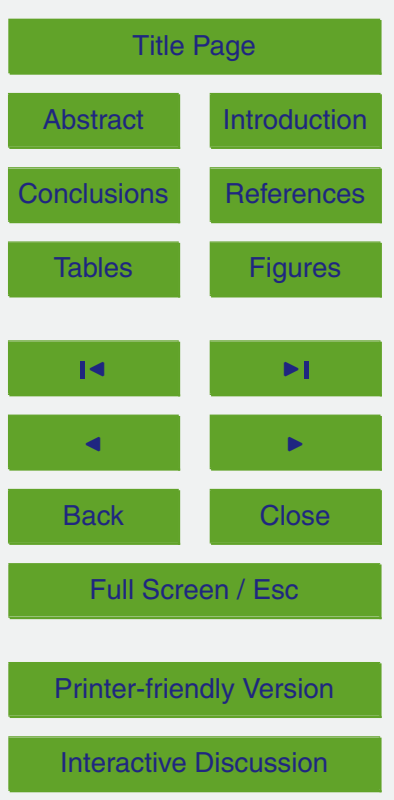


the real world and enable the confrontation to empirical data; only then can existing theories be tested, and unexpected processes be revealed.

Just as their physical and economical counterparts, which were extensively reviewed by Morgan and Morrison (1999), hydrological models are mediators. The traditional 5 distinction between physically-based and conceptual models is then necessarily too simplistic. This distinction relies on the implicit statement that models of both classes are derived from two opposite domains, theory and the world. However, the examples of Newton's pendulum and the economic barometer, to which parallels were drawn in hydrology through HGS and TOPMODEL, showed us that theory and observations are 10 necessary components of all models, whichever their kinds. The distinction between physically-based and conceptual models refers hence at best to the stage, or timing, at which theory and observations are steering model construction. We showed that the degree of theoretical accuracy could be considered relatively high in physically-based models at the moment of their development; however, the physicality progressively decreases upon confrontation with the real world, as the model structure becomes highly influenced by the type and amount of observations required for its application. Conceptual models, on the other hand, are designed from the beginning on to match particular, local conditions. As a result, their relationship to theory and observations stays in principle constant upon application. Physically-based and conceptual models are hence following different construction paths; yet the final result, i.e. the "readyto-use" model tailored for its application, might possibly present no higher, or lower, physical accuracy if it is physically-based or conceptual.

The two traditional classes of models show an additional similarity in their encompassment of a large variety of elements exterior to theory and observations.

25 That is, theory and observations - upon which the distinction between both classes relies - are only two of many more ingredients of model construction. These various elements may play an equally large role in steering model construction as do theory and observations, and would deserve closer attention. Their presence should have at least two important implications on the consideration of hydrological models.

\section{HESSD}

$10,10535-10563,2013$
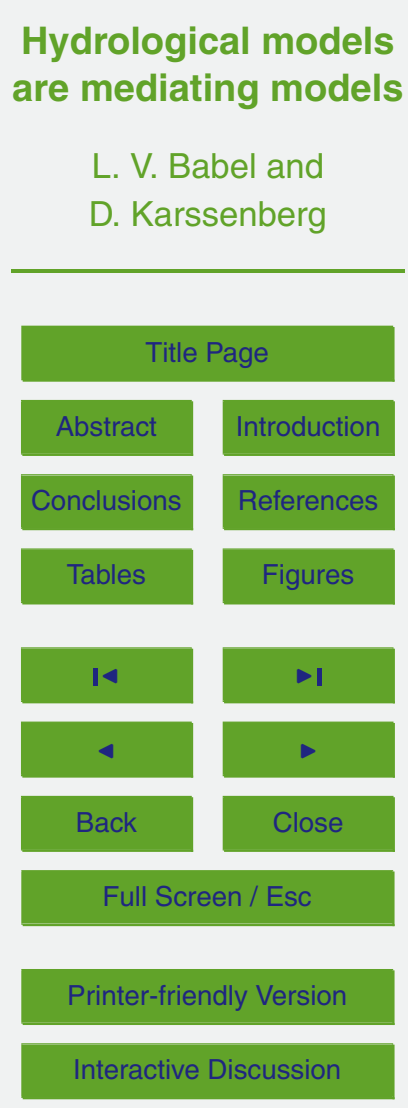
First, these ingredients are reflecting a large panel of constraints exerted on model construction: technological, economical, sociological or even personal ones. Models are hence nothing else than instruments reflecting the environment they were built in at a particular time: the objectives set by the research group, its conception of the 5 system under study, the software and hardware at its disposal, the technical abilities of the modellers ... These components of model construction are in constant evolution, and the constraints might be shifted from one domain to another. They will however be always present; it is precisely because of the multiplicity of their ingredients that models are able to carry the function of instruments of scientific inquiry. This approach 10 of modelling renders it clear that the "final", or "perfect" model will never be reached (Beven, 2001a): a model stays composed of a large mixture of disparate elements, which are the result of choices taken by a group of researcher under a set of varying constraints, in a particular environment and at a particular time.

Second, the variety of ingredients involved in model construction should be taken 15 into consideration when assessing and communicating upon a model's validity. We have argued that not all assumptions and approximations could be justified by theory and observations alone. However, the reasons lying behind a modeller's decision in model construction are rarely explicated in detail in the literature when of sociological kind. Devoting more importance to identifying and communicating on the many factors triggering model construction might increase transparency upon model building. This transparency could in turn benefit to novel model development by helping the identification of areas where different modelling approaches could be used. Finally, we consider that insisting in our communication towards the public on the multiplicity of ingredients involved in model construction could help drawing a better representation of the role and function of models in science - as instruments of scientific inquiry, mediating between theory and the world.

\section{HESSD}

10, 10535-10563, 2013

\section{Hydrological models are mediating models \\ L. V. Babel and \\ D. Karssenberg}

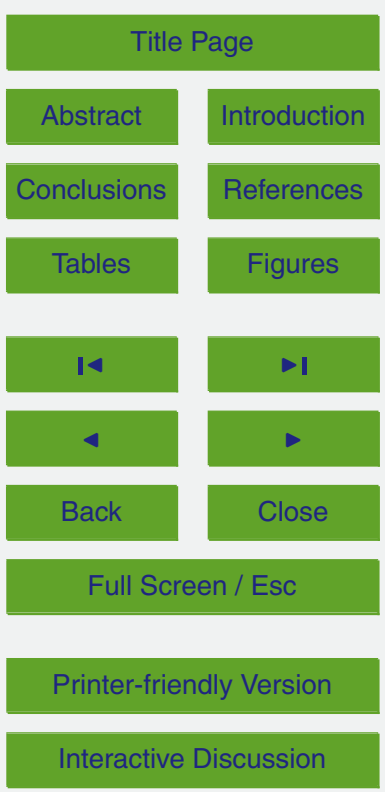




\section{References}

Abott, M. B., Bathurst, J. C., Cunge, J. A., O’Connell, P. E., and Rasmussen, J.: An introduction to the European Hydrological System - Système Hydrologique Européen, "SHE" 1: history and philosophy of a physically-based, distributed modelling system, J. Hydrol., 87, 45-59, 1986.

Abrahart, R. J. and See, L. M.: Neural network modelling of non-linear hydrological relationships, Hydrol. Earth Syst. Sci., 11, 1563-1579, doi:10.5194/hess-11-1563-2007, 2007.

Beven, K.: Changing ideas in hydrology - the case of physically-based models, J. Hydrol., 105, $10 \quad$ 157-172, 1989.

Beven, K.: Prophecy, reality and uncertainty in distributed hydrological modelling, Adv. Water Resour., 16, 41-51, 1993.

Beven, K.: TOPMODEL: a critique, Hydrol. Process., 11, 1069-1085, 1997.

Beven, K.: How far can we go in distributed hydrological modelling?, Hydrol. Earth Syst. Sci., 5, 1-12, doi:10.5194/hess-5-1-2001, 2001a.

Beven, K.: Towards a coherent philosophy for environmental modelling, P. Roy. Soc. Lond. A Mat., 460, 458, 2465-2484, doi:10.1098/rspa.2002.0986, 2002.

Beven, K. J.: Rainfall-Runoff Modelling - The Primer, Wiley, Chichester, UK, 2001b.

Beven, K. J. and Kirkby, M. J.: A physically based, variable contributing area model of basin hydrology, Hydrolog. Sci. J., 24, 43-69, 1979.

Brunner, P. and Simmons, C. T.: HydroGeoSphere: a fully integrated, physically based hydrological model, Groundwater, 50, 170-176, 2012.

Brunner, P., Simmons, C. T., and Cook, P. G.: Spatial and temporal aspects of the transition from connection to disconnection between rivers, lakes and groundwater, J. Hydrology, 376, $25 \quad 159-169,2009$.

Carrera-Hernández, J. J., Mendoza, C. A., Devito, K. J., Petrone, R. M., and Smerdon, B. D.: Reclama tion for aspen revegetation in the Athabasca oil sands: understanding soil water dynamics through unsaturated flow modelling, Can. J. Soil Sci., 92, 103-116, 2012.

Cartwright, N.: How the Laws of Physics Lie, Oxford University Press, Oxford, UK, 1983.

Caswell, H.: Theory and models in ecology: a different perspective, Ecol. Model., 43, 33-44, 1988.
HESSD

10, 10535-10563, 2013

Hydrological models

are mediating models

L. V. Babel and

D. Karssenberg

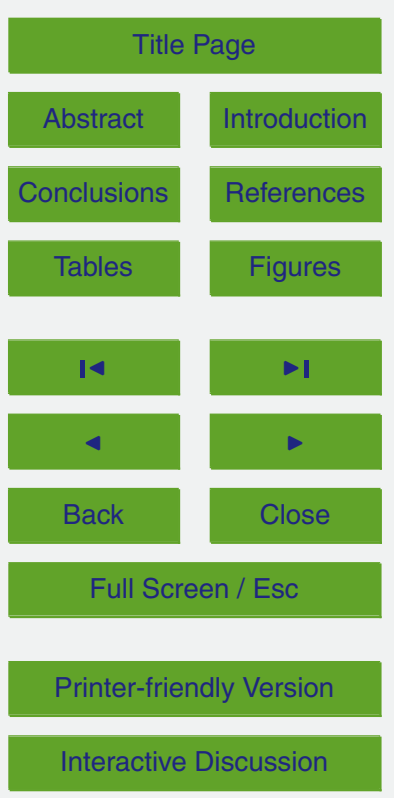


Frei, S., Knorr, K. H., Peiffer, S., and Fleckenstein, J. H.: Surface micro-topography causes hot spots of biogeochemical activity in wetland systems: a virtual modeling experiment, J. Geophys. Res., 117, 1-12, 2012.

Giere, R. N.: Explaining Science: A Cognitive Approach, The University of Chigago Press, Chicago, USA, 62-91, 1988.

Giere, R. N.: Theories, in: A Companion to the Philosophy of Science, edited by: NewtonSmith, W. H., Blackwell, Oxford, UK, 515-524, 2000.

Goderniaux, P., Brouyère, S., Fowler, H. J., Blenkinsop, S., Therrien, R., Orban, P., and Dassargues, A.: Large scale surface-subsurface hydrological model to assess climate change impacts on groundwater reserves, J. Hydrol., 373, 122-138, 2009.

Harman, P. M.: Energy, Force and Matter: The Conceptual Development of Nineteenth-Century Physics, Cambridge University Press, Cambridge, UK, 1982.

Harvard Economic Society: General economic conditions, Rev. Econ. Stat., 8, 201-214, 1932.

Hesse, M.: Models and analogies, in: A Companion to the Philosophy of Science, edited by:

15 Newton-Smith, W. H., Blackwell, Oxford, United Kingdom, 299-307, 2000.

Karssenberg, D.: The value of environmental modelling languages for building distributed hydrological models, Hydrol. Process., 16, 2751-2766, 2002.

Kirkby, M. J.: TOPMODEL: a personal view, Hydrol. Process., 11, 1087-1097, 1997.

Kirk Nordstrom, D.: Models, validation, and applied geochemistry: issues in science, communication, and philosophy, Appl. Geochem., 27, 1899-1919, 2012.

Lehmann, P. and Or, D.: Hydromechanical triggering of landslides: from progressive local failures to mass release, Water Resour., 48, 1-24, 2012.

Lemieux, J.-M., Sudicky, E. A., Peltier, W. R., and Tarasov, L.: Dynamics of groundwater recharge and seepage over the Canadian landscape during the Wisconsinian glaciation, J.

25 Geophys. Res., 113, 18 pp., 2008.

MATLAB: available at: http://www.mathworks.nl/ (last access: 23 April), 2013.

Mattingly, J.: The structure of scientific theory change: models vs. privileged information, Philos. Sci., 72, 365-389, 2005.

McCallum, J. L., Cook, P. G., Brunner, P., and Berhane, D.: Solute dynamics during bank storage flows and implications for chemical base flow separation, Water Resour. Res., 46, 11 pp., 2010.

Morgan, M.: The History of Econometric Ideas, Cambridge University Press, Cambridge, UK, 1990.

Hydrological models are mediating models

L. V. Babel and

D. Karssenberg

Title Page

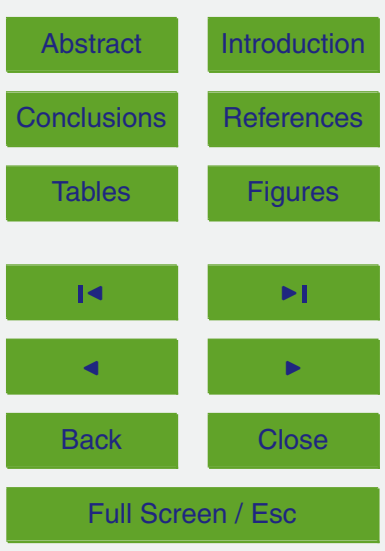

Printer-friendly Version

Interactive Discussion 
Morrison, M.: Where have all the theories gone?, Philos. Sci., 74, 195-228, 2007.

Morrison, M. and Morgan, M. S.: Models as mediating instruments, in: Models as Mediators: Perspectives on Natural and Social Science, edited by: Morgan, M. S. and Morrison, M., Cambridge University Press, Cambridge, UK, 10-37, 1999.

5 Morton, A.: Mathematical models: questions of trustworthiness, Brit. J. Philos. Sci., 44, 659674, 1993.

Mulligan, M.: Modelling catchment hydrology, in: Environmental Modelling: Finding Simplicity in Complexity, edited by: Wainwright, J. and Mulligan, M., Wiley, Chichester, UK, 2005.

Odenbaugh, J.: Idealized, inaccurate but successful: a pragmatic approach to evaluating models in theoretical ecology, Biol. Philos., 20, 231-255, 2005.

Oreskes, N., Shrader-Frechette, K., and Belitz, K.: Verification, validation, and confirmation of numerical models in the earth sciences, Science, 263, 641-646, 2004.

Partington, D., Brunner, P., Therrien, R., Werner, A. D., Dandy, G. C., and Maier, H. R.: A hydraulic mixing cell method to quantify the groundwater component of streamflow within spatially distributed fully integrated surface water-groundwater flow models, Environ. Modell. Softw., 26, 886-898, 2011.

PCRaster: available at: http://pcraster.geo.uu.nl/, last access: 23 April 2013.

Peck, S. L.: Simulation as experiment: a philosophical reassessment for biological modeling, Trends Ecol. Evol., 19, 530-534, 2004.

20 Peck, S. L.: Agend-based models as fictive instantations of ecological processes, Philosophy and Theory in Biology, 4, 1-12, 2012.

Persons, W. M.: An index of general business conditions, Rev. Econ. Stat., 1, 111-205, 1919. Python: available at: http://www.python.org/,last access: 23 April 2013.

R: available at: http://www.r-project.org/, last access: 23 April 2013.

Savenije, H. H. G.: HESS Opinions "The art of hydrology", Hydrol. Earth Syst. Sci., 13, 157161, doi:10.5194/hess-13-157-2009, 2009.

Sivapalan, M.: Pattern, process and function: elements of a unified theory of hydrology at the catchment scale, in: Encyclopedia of Hydrological Science, edited by: Anderson, M. G., Wiley, Chichester, UK, 193-219, 2005.

so Sivapalan, M., Blöschls, G., Zhang, L., and Vertessy, R.: Downward approach to hydrological prediction, Hydrol. Process., 17, 2101-2111, 2003.

Smith, C. and Wise, N.: Energy and Empire: A Biographical Study of Lord Kelvin, Cambridge University Press, Cambridge, UK, 1989.
HESSD

10, 10535-10563, 2013

Hydrological models are mediating models

L. V. Babel and

D. Karssenberg

Title Page

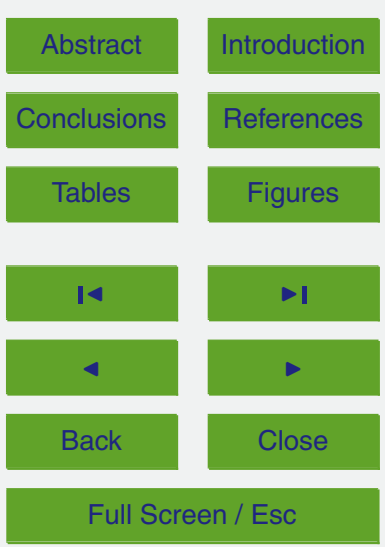

Printer-friendly Version

Interactive Discussion 
Therrien, R., McLaren, R., Sudicky, E., and Panday, S.: HydroGeoSphere: A three-dimensional numerical model describing fully-integrated subsurface and surface flow and solute transport, Manual (Draft), Groundwater Simulation Group, University of Waterloo, Canada, 2010.

van de Bogaard, A.: Past measurements and future prediction, in: Models as Mediators:

5 Perspectives on Natural and Social Science, edited by: Morgan, M. S. and Morrison, M., Cambridge University Press, Cambridge, UK, 282-325, 1999.

Wallace, W.: The Modelling of Nature, Catholic University of America Press, Washington, D.C., USA, 197-237, 1996.

Wanders, N., Karssenberg, D., Bierkens, M., Parinussa, R., de Jeu, R., van Dam, J., and de Jong, S.: Observation uncertainty of satellite soil moisture products determined with physically-based modeling, Remote Sens. Environ., 127, 341-356, 2012.

Weiler, M. and McDonnell, J.: Virtual experiments: a new approach for improving process conceptualization in hillslope hydrology, J. Hydrol., 285, 3-18, 2004.

Wimswatt, W.: False models as a means to truer theories, in: Neutral Models in Biology, edited

15 by: Nitecky, M. and Hoffman, A., Oxford University Press, Oxford, UK, 23-55, 1987.

Winsberg, E.: Science in the age of computer simulation, University of Chicago Press, Chicago, USA, 2010.

L. V. Babel and

D. Karssenberg

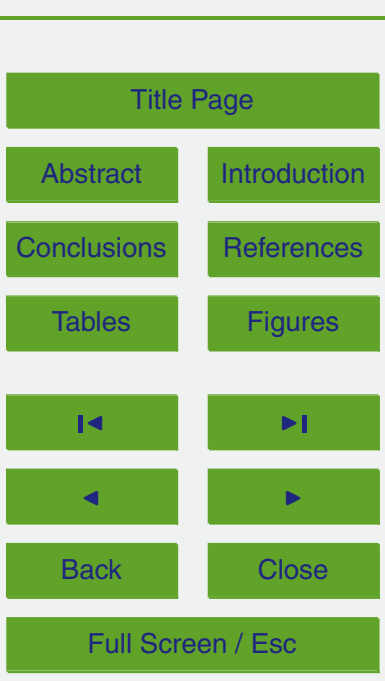

Printer-friendly Version

Interactive Discussion 


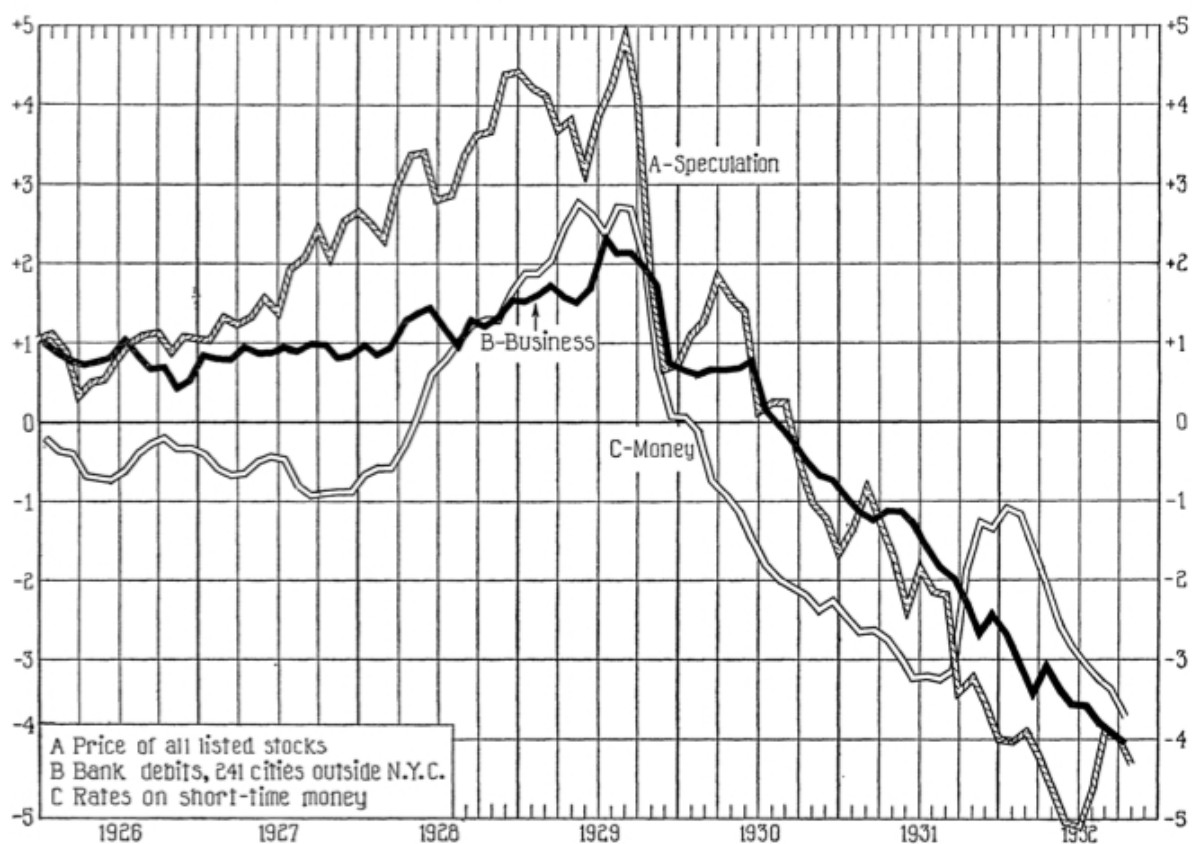

Fig. 1. The economic barometer shown here was constructed by a low-pass filtering of economical variables, classifying them into three economical indexes (speculation, business and money) on the basis of the timing of their fluctuations. The relationships between the three curves are then used as a basis for forecasting (Bullock and Crum, 1932). In this particular example, the business index $(B)$ is declining while the speculation index $(A)$ is increasing; since "there is customarily a lag between a cyclical advance in Curve A and Curve B" (Harvard Economic Society, 1932), this decline is expected to reverse soon (from Harvard Economic Society, 1932).
10, 10535-10563, 2013

Hydrological models are mediating models
L. V. Babel and
D. Karssenberg

Title Page

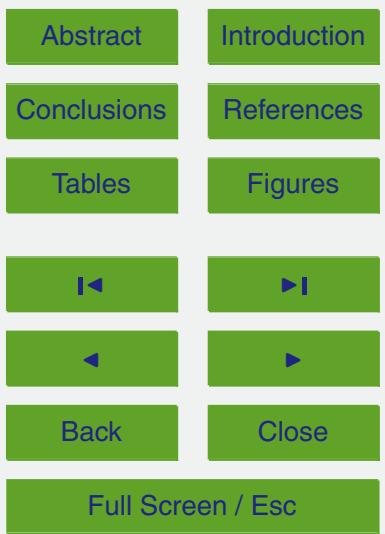

Printer-friendly Version

Interactive Discussion 


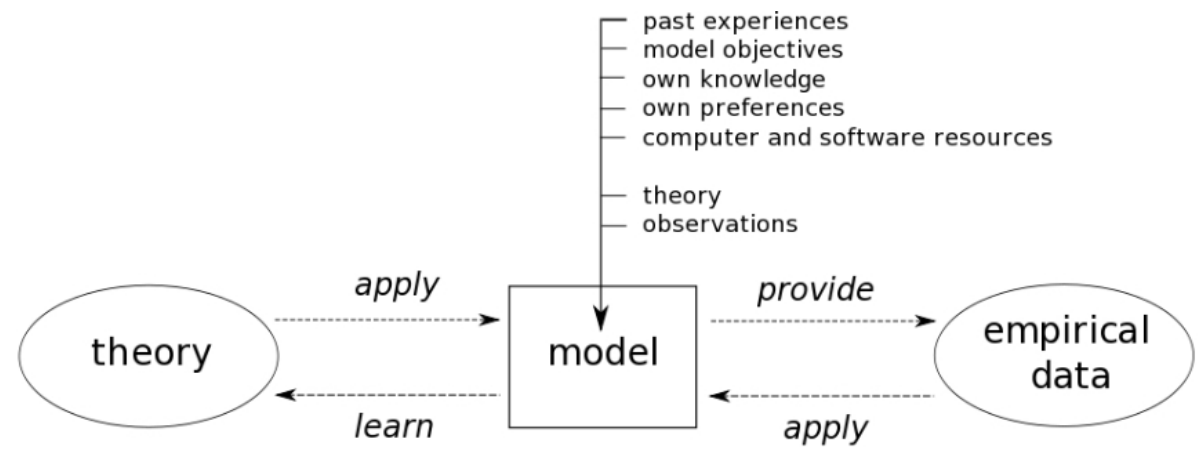

Fig. 2. The construction of hydrological models is steered by theory and empirical data, but also by five further ingredients external to these two domains: past experiences, model objectives, knowledge and preferences of the modeller, as well as computer and software resources. This variety of ingredients enables models to mediate between theory and the world (empirical data), into two directions. First, models mediate between theory and the world by acting as measurement instruments, providing empirical data on the basis of existing theories. Second, models mediate between the world and theory by enabling the confrontation of theories to empirical data, in order to test existing theories or reveal unexpected processes.
Hydrological models are mediating models

L. V. Babel and

D. Karssenberg

Title Page

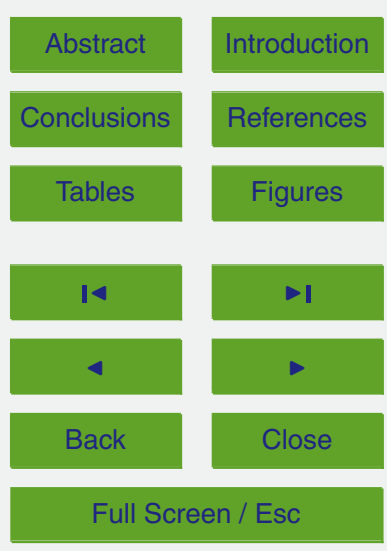

Printer-friendly Version

Interactive Discussion 